\title{
A África do século XXI ${ }^{1}$
}

Daniel Pereira²

Gostaríamos de agradecer, antes de mais, à Reitoria do UniCEUB, através da Assessoria de Assuntos Internacionais, a sua disponibilidade em receber, uma vez mais, o Grupo dos Embaixadores Africanos acreditados no Brasil, a que o UniCEUB se vem associando sempre que solicitado, a demonstrar o seu real interesse pelas questões africanas nas suas mais diversas vertentes. Esse interesse naturalmente tem muito a ver com o fato de o Brasil se encontrar ligado à história e à cultura africanas, de forma indelével, pela contribuição que o negro africano deu à formação da sociedade brasileira.

Desejamos, então, em nome do Grupo dos Embaixadores Africanos acreditados no Brasil e em meu próprio nome, partilhar com os presentes algumas reflexões, que inserimos num texto, cujo título é "A África do século XXI", com o objetivo declarado de trazer ao vosso conhecimento uma outra África, a contrastar com aquela que os grandes mídias mundiais consomem e passam aos seus cidadãos, que ficam confundidos com informações defasadas da realidade.

Efetivamente, o Continente Africano é, amiúde, tão somente confundido com guerras, fome, AIDS, analfabetismo, miséria. Tudo isso é, em parte, verdade, mas a África não é apenas isso. O nosso Continente também produz riqueza, cultura, literatura, história, constroi, paulatinamente a paz, avança a passos firmes, rumo ao progresso e ao desenvolvimento.

\footnotetext{
${ }^{1}$ Grupo Africano de Embaixadores Acreditados em Brasília (Comemoração 'Dia e África' 2009)

${ }^{2}$ Daniel Antônio Pereira é Embaixador de Cabo Verde no Brasil, Ministro Plenipotenciário do quadro diplomático do Ministério dos Negócios Estrangeiros, Cooperação e Comunidades de Cabo Verde. É autor de seis livros sobre a História de Cabo Verde, designadamente, "A situação da ilha de Santiago no $1^{\circ}$ quartel do século XVIII" (duas edições); "Marcos cronológicos da Cidade Velha" (2a edição revista e aumentada no prelo); "Estudos da História de Cabo Verde" (duas edições); "A impotância histórica da Cidade Velha" e "apontamentos históricos sobre a ilha do Fogo"; Ao Encontro da História de Cabo Verde - Manual para o Ensino Secundário (no prelo). Dezenas de artigos publicados em diversas revistas e jornais, nacionais e estrangeiros, tendo igualmente proferido palestras e conferências em várias Universidades em Portugal, Estados Unidos da América e Brasil.
} 
Este mesmo continente que, às vezes, se nos apresenta como um autêntico marasmo, donde nada de bom pode vir, é o mesmo que é o berço da humanidade e pariu civilizações requintadas como a do Egito, Cartago mercantil, impérios como os do Monomotapa (África Austral), Mali ou Songhay (África Ocidental), ou figuras de proa, desde a mais alta antiguidade, como Santo Agostinho; na atualidade, é o mesmo que deu à luz três Prémios Nobel da Literatura (o nigeriano, Wole Soynka, a sul-africana, Nadine Gordimer, o egípcio, Nagib Mahfuz), quatro Prêmios Nobel da Paz, sendo três originários da África do Sul, designadamente, Desmond Tutu, em 1984, Nelson Mandela e Frederik de Klerk, em 1993 e a queniana, Wangari Maathai, em 2004. E por falar em laureados, podemos indicar, igualmente, os nomes dos escritores José Craveirinha de Moçambique ou de Pepetela e Luandino Vieira de Angola, todos Prêmios Camões.

Do seio do nosso Continente, também nasceram, no período contemporâneo, personalidades políticas de envergadura internacional como o ganês, $\mathrm{K}$. Nkrumah, o congolês Patrice Lumumba, o egípcio Gamal Abdel Nasser, o guineense/cabo-verdiano, Amílcar Cabral, Nelson Mandela, entre outros.

Figuras de proa da intelectualidade africana, como o maliano Amadou Hampaté Bâ, o burkinabé Joseph Ki Zerbo e o senegalês Cheikh Anta Diop, que pertenceram àquela geração de africanos que, utilizando as ferramentas metodológicas das escolas europeias operaram uma ruptura epistemológica profunda nos paradigmas dominantes e construíram um discurso que permitiu desconstruir a prosápia europeia sobre o Outro, que dominou as ciências históricas no período colonial; ou então, o egípcio Butrus Butrus Gali e o ganês Koffi Anan, que estiveram durante largos anos à frente de uma poderosa Organização como a das Nações Unidas. Para além de brilhantes professores e pesquisadores que, no Continente mãe ou noutro, fazem progredir a ciência e o saber, a massa anônima dinâmica, as mulheres batalhadoras, comerciantes dinâmicos e criativos. Em suma, os milhões de anônimos. Fazem parte, plenamente, deste milênio!

Do ponto de vista estritamente econômico, o crescimento à volta dos 2,4\% do PIB nos anos 90 deu lugar a um aumento à volta de $4 \%$ anuais entre $2000 \mathrm{e}$ 2004, tendo ultrapassado os $4 \%$ em 2005, sendo que, um grupo superior a 27 países ultrapassou os 5\% em 2007. Angola foi, em 2008, o segundo país com maior crescimento do mundo com mais 20\%, seguido da Mauritânia com 13\%. 
Mas a taxa média africana de crescimento, em 2008, foi de 6,8\%. Aliás, sete das vinte economias com crescimento econômico mais rápido estão situadas no nosso Continente.

Entre os países africanos de língua portuguesa, apenas a Guiné-Bissau ficou abaixo dos $6 \%$ de crescimento em 2007. A proporção da África na produção econômica mundial cresceu 5,5\%, ou seja, mais do que qualquer membro da OCDE. A inflação média no Continente é de um dígito, e em mais de 30 países está abaixo dos $5 \%$.

O crescimento do Investimento Externo Direto (IED) com destino à África cresceu 200\%, entre 2000 e 2005 (saltando de 7 para 23 bilhões de dólares), enquanto a Ásia ficou com um crescimento de apenas $60 \%$. É claro que o ponto de partida da África é mais modesto, mas ainda assim os números são espetaculares e a tendência continua a ser de consolidação.

Muitos se admiram pelo fato de a Bolsa de Valores de Johannesburg ter uma capitalização superior à da Bovespa ou à da Bolsa de Xangai. Outro fator determinante para atrair o financiamento externo tem sido a redução do peso da dívida, que, parcialmente, foi perdoada e em outra grande parte foi eliminada: o maior devedor africano, a Nigéria, pagou toda a sua dívida.

$\mathrm{Na}$ área comercial as exportações africanas cresceram 25\%, em média, nos últimos três anos, até 2008, um desempenho igual ao da China, a ser comparada aos $14 \%$ do resto dos países do Sul.

Mas não é só na economia que a África obtém resultados importantes. Em primeiro lugar, essa evolução não seria possível sem a redução drástica dos conflitos violentos no Continente, que passaram de quinze a praticamente três: Darfur (e suas extensões no Chade e na República Centro-Africana), Somália e pequenos resíduos nos Grandes Lagos (Congo Oriental, Burundi e Norte do Uganda). É verdade que ainda existem conflitos não resolvidos, mas esses conflitos, entretanto, são de baixa intensidade e não provocam grandes perdas de vidas humanas, embora ainda sejam demais.

A melhoria da segurança também é evidenciada pela evolução positiva dos indicadores de criminalidade, delinquência e proliferação de armas ligeiras. 
Também a reforma da Organização de Unidade Africana em União Africana teve um impacto positivo na coordenação dos esforços africanos para a manutenção da paz. A União Africana introduziu, pela primeira vez, princípios escrupulosos de respeito à ordem constitucional, aos direitos humanos e apela a uma avaliação dos pares sobre a governança dos países, o já conhecido Mecanismo Africano de Exame dos Pares (MAEP), o que significa dizer o reconhecimento expresso de que uma governação política, econômica e empresarial sã é indispensável ao desenvolvimento sustentado da África.

No respeitante aos Objetivos de Desenvolvimento do Milênio - consagrados pelas Nações Unidas em 2000 e com o horizonte temporal de 2015 (como meta para a redução pela metade dos índices de pobreza e melhoria de uma série de outros indicadores de desenvolvimento) - a África cada vez mais se polariza em dois grandes grupos.

O primeiro deles é o conjunto de cerca de metade dos países que crescem a ritmo acelerado e que melhoram o acesso à educação, saúde, aumentando o número de mulheres na vida pública (Ruanda, país recém-saído de um genocídio, atingiu a paridade de gênero no Parlamento; a Libéria, outra vítima da guerra civil, elegeu a primeira mulher Presidente), ou conseguindo baixar a incidência do maior inimigo do Continente, o HIV/Aids (como são os casos do Quênia, Zimbábue ou Burkina Faso).

Outro grupo de países não atingiu ainda esse patamar de transformação. A boa notícia é de que aumentou para o triplo a ajuda ao desenvolvimento para a África e, cada vez mais, os países menos avançados são foco de políticas específicas, nas áreas do comércio e do investimento. Progressos científicos permitem hoje melhorar variedades agrícolas, combater a desertificação que assola toda a faixa Sudano-Saheliana, ou aumentar o acesso à água potável. A luta contra a malária, ainda o maior assassino do Continente, está finalmente a merecer a prioridade devida.

Todo o Continente abraça com entusiasmo as novas tecnologias, capazes de catapultar o progresso para o continente mais jovem do planeta. A África tem o maior crescimento de telefonia celular do mundo. Os mercados africanos têm o dobro da expansão média anual da Ásia. 
Entre 1998 e 2003 o crescimento do setor foi de 5.000\%. O número de africanos com acesso a redes de telefonia passou de 10\% em 1999 para 60\% em 2007, prevendo a revista The Economist que em 2010 chegará a 85\%. Os africanos também já se beneficiam do acesso à televisão digital. Existem vários canais de noticiário "24 horas” exclusivamente dedicados à África, alguns sendo emitidos do continente via satélite, como é o caso na África do Sul, Nigéria e Egito.

Os grandes grupos de mídia, com cobertura mundial, tiveram de seguir a onda e iniciaram, nos últimos anos, canais com programação especial para a África, da CNN a MTV. Vários países africanos acolhem hoje centrais de atendimento de países do Norte. Em Accra, Gana, a companhia local TradeNet prepara-se para lançar uma espécie de E-Bay para os produtos agrícolas da África Ocidental.

Dito isso, sublinhemos, mais uma vez, a necessidade das midias darem um pouco mais de atenção ao Continente africano, não tanto nas coisas ruins, que essas quando acontecem têm eco quase que imediato, mas nas coisas boas que nele sucedem todos os dias. Seria um grande serviço que prestariam também ao aumento da auto-estima de todos os afro-brasileiros, cujas raízes se encontram enterradas na África, o berço de toda a Humanidade.

E a talhe de foice, importaria, ainda, fazer aqui, ainda que uma breve referência às relações entre a África e o Brasil, a demonstrar que a aproximação e o aprofundamento das suas relações não é obra do acaso mas fruto de uma estratégia bem pesada e ponderada.

Na verdade, a chegada ao poder do Presidente Lula representou uma nova etapa nas relações com a África. Desde o início, dois objetivos estratégicos do Presidente - o reconhecimento da questão racial no Brasil e uma política externa privilegiando uma parceria estratégica com o Sul - tiveram um enorme impacto no Continente.

As sucessivas visitas do Presidente a mais de duas dezenas de países africanos; as tomadas de posição em fóruns internacionais; a criação de fundos de ajuda inovadores como o UNITAID; a importância dada à CPLP, a defesa do interesse comercial dos mais pobres na OMC, a política de aproximação cultural com a África e a I Cimeira dos Chefes de Estado e de Governo da África e América do Sul, realizada em Abuja, Nigéria, em Novembro de 2006, foram elementos 
importantes nas esferas de decisão com relação ao Continente. A iniciativa de acolher o II Encontro de Intelectuais Africanos e a Diáspora em Salvador da Bahia, em Julho 2006, foi mais uma prova desse interesse peculiar do Brasil.

No mesmo ano, teve lugar a I Cimeira do IBAS (Índia Brasil e África do Sul), com a aprovação de um plano de ação ambicioso. A diplomacia brasileira abriu mais de dezena de novos postos diplomáticos no Continente. Empresas como a Petrobrás, Companhia do Vale do Rio Doce ou a Odebrecht aumentaram sua presença no Continente. O comércio externo com a África cresceu $26 \%$ por ano e 225\% para os países africanos de língua portuguesa, desde 2004. O saldo positivo para o Brasil é da ordem dos 640 milhões de dólares. De todo o modo e de forma geral, entre 2005 e Outubro de 2006, o comércio entre o Brasil e a África mais do que duplicou, passando de 5 bilhões para 12,8 bilhões. E consideremos que, num cenário populacional mundial de 7 bilhões de habitantes, a África contribui com 1 bilhão pessoas. Logo, trata-se de um mercado consumidor que ninguém pode querer negligenciar.

Resumindo, a África está firmemente engajada em tratar os problemas fundamentais ligados à dignidade humana e ao desenvolvimento. É cada vez mais evidente a vontade política e financeira que se tem manifestado entre os seus dirigentes, no sentido de assegurar a boa governação e o estado de direito, investindo no seu capital humano e aplicando políticas de estímulo ao crescimento econômico com vista a diminuir a pobreza. Aliás, como bem se sabe, o crescimento econômico é a condição inicial indispensável à redução da pobreza.

O seu compromisso em assumir as suas responsabilidades em matéria de democracia, direitos humanos, paz e estabilidade no conjunto do Continente tem sido, reiteradas vezes, declarada e, consequentemente, defendida, tanto que, muitos conflitos foram sanados e a democracia, por meio da realização de eleições livres e justas, se vem consolidando em vários países africanos.

Mas devemos reconhecer também sem ambiguidades, que a aspiração da população africana em beneficiar os direitos humanos fundamentais, das oportunidades econômicas e liberdades políticas mencionadas são ainda contrariadas em certos casos e que os progressos na realização dos Objetivos de 
Desenvolvimento do Milênio (ODM) continuam insuficientes em numerosos países. Ou seja, muito caminho há ainda para andar. Mas estamos a percorrê-lo na direção certa, rumo ao desenvolvimento e ao bem estar da nossa população, o mais rapidamente possível. Estamos convencidos de que atingiremos a meta.

Há cinquenta anos, ninguém ousaria imaginar que a China seria hoje a terceira potência econômica do Planeta. E, segundo as previsões do banco americano que mais negócios tem com a China, o JP Morgan, em 2040 este país terá a maior economia do mundo. Isso apesar do seu sistema político.

A África com as suas potencialidades econômicas certamente ganhará outros rumos. Que não haja dúvidas sobre isso! Gerações de jovens educados e treinados em cidadania plena e de critérios de qualidade científicos ganham cada vez mais o espaço de seres que lideram o seu presente. Isso é a África!

Muito Obrigado. 